\title{
Serum STLT-1 and bilirubin levels in patients with acute coronary syndrome and correlation with prognosis
}

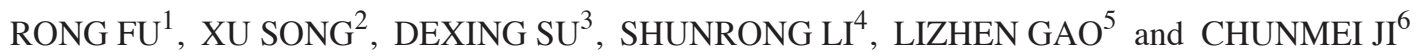 \\ Departments of ${ }^{1}$ Cardiology and ${ }^{2}$ Respiratory Medicine, People's Hospital of Rizhao, Rizhao, Shandong 276800; \\ Departments of ${ }^{3}$ Cardiology, ${ }^{4}$ Critical Care Medicine and ${ }^{5}$ Clinical Laboratory, People's Hospital of Zhangqiu, Jinan, \\ Shandong 250200; ${ }^{6}$ Department of Clinical Laboratory, People's Hospital of Weifang, Weifang, Shandong 261000, P.R. China
}

Received September 20, 2017; Accepted March 29, 2018

DOI: $10.3892 /$ etm.2018.6137

\begin{abstract}
The serum triggering receptor expressed on myeloid cell (TREM)-like transcription factor-1 [soluble TREM-like transcript-1 (STLT-1)] and bilirubin levels were investigated in patients with acute coronary syndrome and the correlation with prognosis. A total of 125 patients of acute coronary syndrome admitted to the Department of Cardiology in People's Hospital of Rizhao were selected, including 45 cases with ST-segment elevation myocardial infarction (STEMI), 36 cases with non-ST-elevation myocardial infarction (NSTEMI) and 44 cases with unstable angina pectoris (UAP), while 48 subjects were enrolled as the normal control. The serum STLT-1 and bilirubin levels on admission and on the 3rd, 7 th and 10th day after admission of patients in each group were respectively determined, the level changes of these two indicators in serum during the initial stage of acute coronary syndrome were analyzed, and their effects on prognosis of patients were analyzed. STLT-1 levels in groups STEMI, NSTEMI and UAP were higher than those in the normal control group, and serum levels of STLT-1 in groups STEMI and NSTEMI were higher than those in group UAP. Bilirubin levels in groups STEMI, NSTEMI and UAP were lower than those in the normal control group, and serum levels of bilirubin in groups STEMI and NSTEMI were lower than those in group UAP. The proportions of complications in patients of groups STEMI and NSTEMI were significantly higher than those in group UAP $(\mathrm{P}<0.05)$. The results showed that the timely and effective treatment administered to patients with acute coronary syndrome during the initial stage to reduce the level of STLT-1 in serum and enhance bilirubin to a relatively high level is conducive in ameliorating the prognosis of patients, which is of clinical significance.
\end{abstract}

Correspondence to: Dr Chunmei Ji, Department of Clinical Laboratory, People's Hospital of Weifang, 151 Guangwen Street, Kuiwen, Weifang, Shandong 261000, P.R. China

E-mail:cxm4gh@163.com

Key words: acute coronary syndrome, STLT-1, bilirubin

\section{Introduction}

In recent years, with the gradual ageing of the population and the change of dietary habits in China, the incidence of cardiovascular disease has increased gradually. Coronary heart disease has received most attention from medical workers because of its high fatality rate, especially the acute onset of coronary heart disease $(1,2)$. Acute coronary syndromes mainly include ST-segment elevation myocardial infarction (STEMI), non-ST-elevation myocardial infarction (NSTEMI) and unstable angina pectoris (UAP).

At present, coronary angiography is regarded as the gold standard in the diagnosis of coronary heart disease, which has the disadvantages of high cost and inconvenience. Thus, it is crucial to conduct the early diagnosis and effective treatment by combining with enquiry about patients' medical history, as well as physical and laboratory examination (3-5). STLT-1 has a common genetic origin with the triggering receptor expressed on myeloid cells (TREM), which is a natural immune receptor activated by associated receptor proteins. Bilirubin is a bile pigment, which is the main metabolite of iron porphyrin compounds in vivo. It has antioxidant function and can inhibit the oxidation of linoleic acid and phospholipids.

In this study, the serum soluble TREM-like transcript-1 (STLT-1) and bilirubin levels in each group of patients were determined, so as to estimate the early diagnosis and prognosis.

\section{Patients and methods}

General data. A total of 125 patients of acute coronary syndrome and 48 cases with normal coronary angiography admitted to People's Hospital of Rizhao (Rizhao, China) from January 2015 to September 2016 were selected, and all of them met the standards in the guidelines of the American College of Cardiology and the American Heart Association for coronary syndromes in 2012 (6). There were 45 cases with STEMI, 36 cases with NSTEMI and 44 cases with UAP. The selected patients had no severe acute or chronic infection, organ dysfunction or malignancy. The statistical analysis revealed that there were no significant differences in age, sex, dietary habit and blood lipid among the patients admitted to the hospital (Table I), indicating that the data were comparable. 
Table I. Comparison of general data among the four groups.

\begin{tabular}{lcccccc}
\hline General data & Group STEMI & Group NSTEMI & Group UAP & Group normal control & $\chi^{2} / \mathrm{t}$ & P-value \\
\hline Total & 45 & 36 & 44 & 48 & & \\
Sex $(\%)$ & & & & & & \\
Male & 25 & 19 & 21 & 24 & 3.06 & 0.36 \\
Female & 20 & 17 & 23 & 24 & 3.06 & 0.36 \\
Age (years) & $57 \pm 3.24$ & $54 \pm 3.09$ & $52 \pm 3.11$ & $52 \pm 3.09$ & 1.23 & 0.29 \\
Cholesterol (mmol/l) & $6.12 \pm 1.2$ & $6.02 \pm 1.1$ & $5.89 \pm 1.2$ & $5.99 \pm 1.2$ & 1.11 & 0.59 \\
\hline
\end{tabular}

STEMI, ST-segment elevation myocardial infarction; NSTEMI, non-ST-elevation myocardial infarction; UAP, unstable angina pectoris.

Table II. Comparison of serum levels of STLT-1 between and after treatment in each group of patients (pg/ml).

\begin{tabular}{|c|c|c|c|c|c|c|c|}
\hline \multirow[b]{2}{*}{ Groups } & \multirow[b]{2}{*}{ Cases (no.) } & \multicolumn{4}{|c|}{ STLT-1 } & \multirow[b]{2}{*}{$\mathrm{F}$} & \multirow[b]{2}{*}{ P-value } \\
\hline & & At admission & $\begin{array}{c}\text { 3rd day } \\
\text { after treatment }\end{array}$ & $\begin{array}{c}\text { 7th day } \\
\text { after treatment }\end{array}$ & $\begin{array}{c}\text { 10th day } \\
\text { after treatment }\end{array}$ & & \\
\hline STEMI & 45 & $541.2 \pm 132.7$ & $503.7 \pm 122.5^{\mathrm{a}-\mathrm{c}}$ & $361.2 \pm 103.1^{\mathrm{a}-\mathrm{c}}$ & $225.9 \pm 73.2^{\mathrm{a}-\mathrm{c}}$ & 8.05 & $<0.05$ \\
\hline NSTEMI & 36 & $527.6 \pm 140.1$ & $505.1 \pm 117.7^{\mathrm{a}-\mathrm{c}}$ & $322.5 \pm 98.2^{\mathrm{a}-\mathrm{c}}$ & $213.1 \pm 76.1^{\mathrm{a}, \mathrm{c}}$ & 8.16 & $<0.05$ \\
\hline UAP & 44 & $518.7 \pm 126.2$ & $469.2 \pm 132.7^{\mathrm{a}, \mathrm{c}}$ & $276.3 \pm 85.1^{\mathrm{a}, \mathrm{c}}$ & $156.2 \pm 55.4^{\mathrm{a}, \mathrm{c}}$ & 8.22 & $<0.05$ \\
\hline Normal control & 48 & $498.3 \pm 119.4$ & $254.2 \pm 85.3^{\mathrm{c}}$ & $112.4 \pm 41.5^{\mathrm{c}}$ & $85.1 \pm 33.8^{c}$ & 8.21 & $<0.05$ \\
\hline $\mathrm{F}$ & & 1.23 & 8.46 & 8.25 & 8.66 & & \\
\hline P-value & & $>0.05$ & $<0.05$ & $<0.05$ & $<0.05$ & & \\
\hline
\end{tabular}

${ }^{\mathrm{a} C}$ Compared with the normal control group, a statistically significant difference, $\mathrm{P}<0.05$; ${ }^{\mathrm{b}} \mathrm{Compared}$ with the group UAP, a statistically significant difference, $\mathrm{P}<0.05$. 'The value at each time point is different from that at the previous point, and statistically significant, $\mathrm{P}<0.05$. STLT-1, soluble TREM-like transcript-1; STEMI, ST-segment elevation myocardial infarction; NSTEMI, non-ST-elevation myocardial infarction; UAP, unstable angina pectoris.

The study was approved by the medical Ethics Committee of People's Hospital of Rizhao, and the patients or their families signed informed consent.

Methods. Venous blood (3 ml) was collected using vacuum anticoagulation blood collection tube from the patients on admission. Patients in STEMI, NSTEMI and UAP groups were treated with aspirin (Bayer AG, Leverkusen, Germany) at a dose of $100 \mathrm{mg}$ Qd and clopidogrel (Sanofi S.A., Paris, France) at a dose of $75 \mathrm{mg}$ Qd. Fasting blood was extracted from each patient on the $3 \mathrm{rd}$, 7th and 10th day after treatment. Serum levels of STLT-1 were determined using ELISA kit (Oumeng, Biotechnology Co. Ltd., Beijing, China). An ADVIA1800 automatic biochemical analyzer was used to determine serum bilirubin levels (Siemens, Berlin, Germany). The patients were followed up by telephone for a year at regular intervals after discharge. The prognosis of the patients was analyzed.

Statistical analysis. Statistical Product and Service Solutions (SPSS) 17.0 software (SPSS, Inc., Chicago, IL, USA) was used for statistical analysis. Measurement data are expressed as mean \pm standard deviation. The analysis of variance was adopted for comparison among the groups and the post hoc test used was Dunnett test, and t-test was utilized for comparison between the groups. The Chi-square test was used for enumeration data. $\mathrm{P}<0.05$ was set as the test level.

\section{Results}

Comparison of serum levels of STLT-1 before and after treatment in each group of patients. At admission, there were no statistically significant differences in serum STLT-1 among the groups $(\mathrm{P}>0.05)$. Compared with the normal control group, the serum levels of serum STLT-1 in groups STEMI, NSTEMI and UAP were higher, and the differences were statistically significant $(\mathrm{P}<0.05)$. Moreover, the serum STLT levels in groups STEMI and NSTEMI were higher than those in group UAP, and the differences were statistically significant $(\mathrm{P}<0.05)$. There was no statistically significant difference in comparison with serum STLT-1 level between groups STEMI and NSTEMI $(\mathrm{P}>0.05)$. With the prolongation of treatment time, STLT-1 level in groups STEMI, NSTEMI and UAP was decreased $(\mathrm{P}<0.05)$, and the value at each time point was different from that at the previous point, which was statistically significant (Table II). 
Table III. Comparison of serum levels of bilirubin between and after treatment in each group of patients.

\begin{tabular}{|c|c|c|c|c|c|c|c|}
\hline \multirow[b]{2}{*}{ Groups } & \multirow[b]{2}{*}{ Cases (no.) } & \multicolumn{4}{|c|}{ Bilirubin } & \multirow[b]{2}{*}{$\mathrm{F}$} & \multirow[b]{2}{*}{ P-value } \\
\hline & & At admission & $\begin{array}{c}\text { 3rd day } \\
\text { after treatment }\end{array}$ & $\begin{array}{l}\text { 7th day } \\
\text { after treatment }\end{array}$ & $\begin{array}{c}10 \text { th day } \\
\text { after treatment }\end{array}$ & & \\
\hline STEMI & 45 & $10.21 \pm 3.16$ & $12.45 \pm 3.21^{\mathrm{a}-\mathrm{c}}$ & $13.68 \pm 2.84^{\mathrm{a}-\mathrm{c}}$ & $15.42 \pm 2.54^{\mathrm{a}-\mathrm{c}}$ & 8.78 & $<0.05$ \\
\hline NSTEMI & 36 & $10.95 \pm 2.69$ & $12.89 \pm 2.58^{\mathrm{a}-\mathrm{c}}$ & $14.31 \pm 2.73^{\mathrm{a}-\mathrm{c}}$ & $15.67 \pm 2.21^{\mathrm{a}-\mathrm{c}}$ & 8.84 & $<0.05$ \\
\hline UAP & 44 & $13.48 \pm 3.09$ & $14.53 \pm 2.42^{\mathrm{a}, \mathrm{c}}$ & $15.24 \pm 2.42^{\mathrm{a}, \mathrm{c}}$ & $15.89 \pm 2.16^{\mathrm{a}, \mathrm{c}}$ & 9.02 & $<0.05$ \\
\hline Normal control & 48 & $16.57 \pm 1.96$ & $16.79 \pm 1.89^{c}$ & $16.63 \pm 1.92^{c}$ & $16.72 \pm 1.95^{\mathrm{c}}$ & 9.21 & $<0.05$ \\
\hline $\mathrm{F}$ & & 1.23 & 8.46 & 8.25 & 8.66 & & \\
\hline P-value & & $>0.05$ & $<0.05$ & $<0.05$ & $<0.05$ & & \\
\hline
\end{tabular}

${ }^{\mathrm{a} C o m p a r e d ~ w i t h ~ t h e ~ n o r m a l ~ c o n t r o l ~ g r o u p, ~ a ~ s t a t i s t i c a l l y ~ s i g n i f i c a n t ~ d i f f e r e n c e, ~} \mathrm{P}<0.05$; ${ }^{\mathrm{b}} \mathrm{Compared}$ with the group UAP, a statistically significant difference, $\mathrm{P}<0.05$. 'The value at each time point is different from that at the previous point, which is statistically significant, $\mathrm{P}<0.05$. STEMI, ST-segment elevation myocardial infarction; NSTEMI, non-ST-elevation myocardial infarction; UAP, unstable angina pectoris.

Table IV. Comparison of complications in the three groups of patients with acute coronary syndrome [n (\%)].

\begin{tabular}{lccccc}
\hline Groups & Cases (no.) & Myocardial infarction & Intractable angina pectoris & Deep vein thrombosis & Cardiac death \\
\hline STEMI & 45 & $6(13.3 \%)^{\mathrm{a}}$ & $9(20 \%)^{\mathrm{a}}$ & $4(8.9 \%)^{\mathrm{a}}$ & $2(4.4 \%)$ \\
NSTEMI & 36 & $5(13.8 \%)^{\mathrm{a}}$ & $8(22.2 \%)^{\mathrm{a}}$ & $4(11.1 \%)^{\mathrm{a}}$ & $2(5.6 \%)$ \\
UAP & 44 & $3(6.8 \%)$ & $13(29.5 \%)$ & $2(4.5 \%)$ & $1(2.3 \%)$ \\
$\chi^{2}$ & & 3.23 & 2.39 & $<.67$ & 2.45 \\
P-value & & $<0.05$ & $<0.05$ & $<0.05$ & $<0.05$ \\
\hline
\end{tabular}

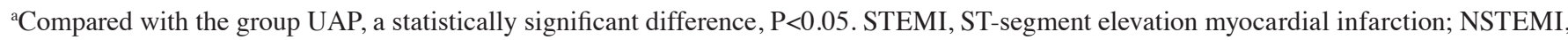
non-ST-elevation myocardial infarction; UAP, unstable angina pectoris; DVT, deep vein thrombosis.

Comparison of serum levels of bilirubin before and after treatment in each group of patients. At admission, there were no statistically significant differences in serum bilirubin among the groups $(\mathrm{P}>0.05)$. Compared with the normal control group, the serum levels of serum bilirubin in groups STEMI, NSTEMI and UAP were lower, and the differences were statistically significant $(\mathrm{P}<0.05)$. Moreover, the serum bilirubin levels in groups STEMI and NSTEMI were lower than those in group UAP, and the differences were statistically significant $(\mathrm{P}<0.05)$. There was no statistically significant difference in comparison with serum bilirubin level between groups STEMI and NSTEMI $(\mathrm{P}>0.05)$. With the prolongation of treatment time, bilirubin level in groups STEMI, NSTEMI and UAP was increased $(\mathrm{P}<0.05)$, and the value at each time point was different from that at the previous point, which was statistically significant (Table III).

Complications in the three groups of patients with acute coronary syndrome. The comparison in prognosis of the patients in the later stage revealed that the proportions in the occurrence of myocardial infarction, intractable angina pectoris and deep vein thrombosis (DVT) were significantly increased in groups STEMI and NSTEMI compared with those in group UAP, and the differences were statistically significant (Table IV).

\section{Discussion}

Coronary heart disease derives from coronary atherosclerosis caused by various risk factors, thus, leading to stenosis or obstruction of the blood vessels, further inducing myocardial hypoxia, or even infarction (7). In recent years, with the process of aging and dietary changes, the incidence of coronary heart disease in China is on the rise. If acute coronary syndrome fails to be diagnosed in time and treated effectively, it will bring great burden to the family and society due to its extremely high mortality rate (8). Therefore, the early diagnosis and treatment of coronary syndrome and the reduction of certain risk indicators are of great importance to rescue the endangered myocardium and ameliorate the prognosis of patients with acute coronary syndrome.

STLT-1 is a protein produced by the cleavage of TLT-1 on the surface of platelets. When the body has an inflammatory response due to various reasons, the level of STLT-1 in the serum may increase significantly $(9,10)$. Related studies indicate that STLT-1 has a promoting role in coronary heart disease. It plays a regulatory role in platelets, leukocytes and endothelial cells, which mainly adhere to vascular endothelial cells by promoting actin polymerization, thus inducing the occurrence of atherosclerosis and promoting the development of coronary heart disease $(11,12)$. The study 
by Esponda et al (13) indicates that STLT-1 is remarkably elevated in the serum of patients with acute coronary syndromes. The present study also confirmed that serum level of STLT-1 in patients with acute coronary syndromes was higher than that in controls, which was consistent with the above findings. The present study demonstrated that the serum levels of STLT-1 in groups STEMI and NSTEMI were higher than those in group UAP, and the proportions of complications in groups STEMI and NSTEMI were significantly higher than those in group UAP. In recent years, the study of bilirubin has indicated that it plays an important role in cardiovascular and cerebrovascular diseases. Bilirubin is a powerful antioxidant in the body, and different types of bilirubin are effective antioxidants that can scavenge oxygen free radicals from the body and protect low-density lipoproteins in the body, in order to resist the damage to the blood vessel and reduce the possibility of atherosclerosis $(14,15)$. Studies worldwide have shown that the level of bilirubin in serum is negatively-related to the incidence of coronary heart disease $(16,17)$. This study revealed that the serum bilirubin levels in groups STEMI, NSTEMI and UAP were lower than those in the normal control group, and the serum bilirubin levels in groups STEMI and NSTEMI were lower than those in group UAP.

The present study indicated that the serum level of STLT-1 was elevated with the increase of severity of acute coronary syndrome, which could gradually decrease through the effective treatment, and patients with lower STLT-1 level in the group UAP had a relatively low proportion of severe complications. The bilirubin level was lower in group STEMI than that in the normal control and UAP groups, which could be gradually enhanced after treatment, and patients with higher bilirubin level in the group UAP had a relatively low proportion of severe complications. In terms of prognosis, patients with STEMI and NSTEMI were more severe than patients with UAP. Myocardial cell damage was observed in STEMI and NSTEMI groups. It is speculated that the prognosis of STEMI and NSTEMI is worse than that of UAP. Levels of STLT-1 and bilirubin in STEMI and NSTEMI groups were also higher than those in UAP. However, further studies are needed to investigate the mechanism.

Therefore, we believe that the timely and effective treatment administered to patients with acute coronary syndrome during the initial stage to reduce the level of STLT-1 in serum and enhance bilirubin to a relatively high level is conducive in ameliorating the prognosis of patients, which has an important clinical significance.

\section{Acknowledgements}

Not applicable.

\section{Funding}

No funding was received.

\section{Availability of data and materials}

The datasets used and/or analyzed during the current study are available from the corresponding author on reasonable request.

\section{Authors' contributions}

RF wrote the manuscript. RF and XS were responsible for collecting the clinical and laboratory information. DS and SL analyzed venous blood. LG and CJ contributed to follow-up and statistical analysis. All authors read and approved the final manuscript.

\section{Ethics approval and consent to participate}

The study was approved by the medical Ethics Committee of People's Hospital of Rizhao (Rizhao, China) and the patients or their families signed the informed consent.

\section{Consent for publication}

Not applicable.

\section{Competing interests}

The authors declare that they have no competing interests.

\section{References}

1. Colantonio LD, Gamboa CM, Richman JS, Levitan EB, Soliman EZ, Howard G and Safford MM: Black-white differences in incident fatal, nonfatal, and total coronary heart disease. Circulation 136: 152-166, 2017.

2. Liu Q, Lichtenstein AH, Matthan NR, Howe CJ, Allison MA Howard BV, Martin LW, Valdiviezo C, Manson JE, Liu S, et al: Higher lipophilic index indicates higher risk of coronary heart disease in postmenopausal women. Lipids 52: 687-702, 2017.

3. Song P, Wang SX and Wang JJ: The application value of 64 slice spiral CT coronary angiography in the diagnosis of coronary heart disease. J Integr Tradit Chin W Med Cerebrovasc Dis 10: 137-139, 2012.

4. Anderson L, Brown JP, Clark AM, Dalal H, Rossau HK, Bridges $\mathrm{C}$ and Taylor RS: Patient education in the management of coronary heart disease. Cochrane Database Syst Rev 6: CD008895, 2017.

5. Svavarsdóttir MH, Sigurðardóttir ÁK and Steinsbekk A: Knowledge and skills needed for patient education for individuals with coronary heart disease: The perspective of health professionals. Eur J Cardiovasc Nurs 15: 55-63, 2016.

6. Jin J: JAMA patient page. Testing for 'silent' coronary heart disease. JAMA 312: 858-859, 2014.

7. Wang BH, Wang H, Yang CZ, Hu KL and Zhou K: Study on the status of discharge readiness and its influencing factors in patients with coronary heart disease. Chung Hua Hu Li Tsa Chih 52: 138-143, 2017 (In Chinese).

8. Song Q and Chen CX: Current status of health self-management among elderly patients with coronary heart disease in Hebei province. China Pub Health 8: 1-5, 2016.

9. Barrow AD, Astoul E, Floto A, Brooke G, Relou IA, Jennings NS, Smith KG, Ouwehand W, Farndale RW, Alexander DR and Trowsdale J: Cutting edge: TREM-like transcript-1, a platelet immunoreceptor tyrosine-based inhibition motif encoding costimulatory immunoreceptor that enhances, rather than inhibits, calcium signaling via SHP-2. J Immunol 172: 5838-5842, 2004.

10. Morales J, Villa K, Gattis J, Castro W, Colon K, Lubkowski J, Sanabria P, Hunter R and Washington AV: Soluble TLT-1 modulates platelet-endothelial cell interactions and actin polymerization. Blood Coagul Fibrinolysis 21: 229-236, 2010.

11. Adukpo S, Gyan BA, Ofori MF, Dodoo D, Velavan TP and Meyer CG: Triggering receptor expressed on myeloid cells 1 (TREM-1) and cytokine gene variants in complicated and uncomplicated malaria. Trop Med Int Health 21: 1592-1601, 2016.

12. Derive M, Bouazza Y, Sennoun N, Marchionni S, Quigley L, Washington V, Massin F, Max JP, Ford J, Alauzet C, et al: Soluble TREM-like transcript-1 regulates leukocyte activation and controls microbial sepsis. J Immunol 188: 5585-5592, 2012. 
13. Esponda OL, Hunter R, Del Río JR and Washington AV: Levels of soluble TREM-like transcript 1 in patients presenting to the emergency department with chest pain. Clin Appl Thromb Hemost 21: 30-34, 2015.

14. Zhang XJ, Sun TW, Kan QC, Yao HM, Wan YD, Yao R, Guan FX, Guo CQ, Zhang SG, Sun WJ, et al: Serum total bilirubin and long-term outcome in patients undergoing percutaneous coronary intervention. Clin Invest Med 37: E345-E351, 2014.

15. Chintanaboina J, Haner MS, Sethi A, Patel N, Tanyous W, Lalos A and Pancholy S: Serum bilirubin as a prognostic marker in patients with acute decompensated heart failure. Korean J Intern Med (Korean Assoc Intern Med) 28: 300-305, 2013.

16. Ozturk M, Askın L, Ipek E, Demirelli S, Turan OE, Yıldırım E, Ermis E, Kalkan K and Delice O: The role of serum bilirubin levels in predicting troponin positivity in non-ST-segment elevation acute coronary syndrome. Angiology 68: 414-418, 2017.
17. Tanındı A, Erkan AF, Alhan A and Töre HF: Arterial stiffness and central arterial wave reflection are associated with serum uric acid, total bilirubin, and neutrophil-to-lymphocyte ratio in patients with coronary artery disease. Anatol J Cardiol 15: 396-403, 2015.

(i) (9) This work is licensed under a Creative Commons Attribution-NonCommercial-NoDerivatives 4.0 International (CC BY-NC-ND 4.0) License. 